\title{
C-Tactile Afferents: Cutaneous mediators of oxytocin release during affiliative tactile interactions?
}

\author{
SUSANNAH WALKER ${ }^{1 *}$, PAULA TROTTER $^{1}$, WILL SWANEY ${ }^{1}$, ANDREW MARSHALL $^{1} \&$ FRANCIS $^{\text {SRAN }}$ \\ MCGLONE ${ }^{1,2}$ \\ 1. Research Centre for Brain \& Behaviour, School of Natural Sciences \& Psychology, Liverpool John Moores University, \\ Liverpool, L3 3AF, UK. \\ 2. Institute of Psychology, Health and Society, University of Liverpool, UK.
}

\author{
*Corresponding Author \\ e-mail: s.c.walker@ljmu.ac.uk \\ Tel.: +44 1519046332 \\ Address: $\quad$ School of Natural Sciences \& Psychology, \\ Liverpool John Moores University \\ Byrom Street \\ Liverpool \\ L3 $3 \mathrm{AF}$ \\ UK.
}

Journal: Neuropeptides

FIGURES: 2 


\begin{abstract}
Low intensity, non-noxious, stimulation of cutaneous somatosensory nerves has been shown to trigger oxytocin release and is associated with increased social motivation, plus reduced physiological and behavioural reactivity to stressors. However, to date, little attention has been paid to the specific nature of the mechanosensory nerves which mediate these effects. In recent years, the neuroscientific study of human skin nerves (microneurography studies on single peripheral nerve fibres) has led to the identification and characterisation of a class of touch sensitive nerve fibres named C-Tactile afferents. Neither itch nor pain receptive, these unmyelinated, low threshold mechanoreceptors, found only in hairy skin, respond optimally to low force/velocity stroking touch. Notably, the speed of stroking which c-tactile afferents fire most strongly to is also that which people perceive to be most pleasant. The social touch hypothesis posits that this system of nerves has evolved in mammals to signal the rewarding value of physical contact in nurturing and social interactions. In support of this hypothesis, in this paper we review the evidence that cutaneous stimulation directly targeted to optimally activate c-tactile afferents reduces physiological arousal, carries a positive affective value and, under healthy conditions, inhibits responses to painful stimuli. These effects mirror those, we also review, which have been reported following endogenous release and exogenous administration of oxytocin. Taken together this evidence suggests c-tactile afferent stimulation may mediate oxytocin release during affiliative tactile interactions.
\end{abstract}

Keywords: Oxytocin; Social; Pleasant Touch; Pain, C-fibre; C-Tactile afferent 


\section{Introduction}

Oxytocin is synthesized and released from the magnocellular neurons of the paraventricular (PVN) and supraoptic nuclei (SON) of the hypothalamus (Stoop, 2014). Magnocellular oxytocin neurons of the PVN and SON project to the posterior pituitary from where oxytocin enters the circulation to induce numerous peripheral effects, including its involvement in lactation and parturition (Yang et al., 2013). Oxytocin receptors have also been identified throughout the central nervous system (CNS) and it is here, primarily through site specific interactions with the ascending monoamine systems, as well as with other neuropeptides, it facilitates a range of sensory and psychological processes essential for adaptive social behaviour, such as pair bonding and attachment formation (Insel and Young, 2001; Liu and Wang, 2003; Mitre et al., 2016; Yoshida et al., 2009).

Mechanistically, many of oxytocin's central effects on adaptive social behaviour relate to its ability to promote sensitivity to socially relevant cues and inhibit hypothalamic-pituitaryadrenal (HPA) responsivity to stressors (Lee et al., 2009). Oxytocin can also modulate parasympathetic activity by stimulating the dorsal motor nucleus of the vagus nerve (Charpak et al., 1984). Peripherally, the neurobiological basis of oxytocin release in both labour and breastfeeding is stimulation of sensory nerves within the cervix and nipple respectively. A range of studies have shown that oxytocin is also released centrally in response to non-noxious activation of sensory nerves in the skin (for review Uvnas-Moberg et al., 2015). However, to date, despite the wealth of evidence that it is specifically gentle, dynamic, warm, cutaneous stimulation delivered in socially relevant contexts that optimally triggers oxytocin release, surprisingly little interest has been has been paid to the specific nature of the sensory nerves meditating this effect.

In this review we make the case that a particular sub-class of unmyelinated c-fibre afferent responds optimally to exactly the sort of stimulation that has been associated with oxytocin release and furthermore the physiological and behavioural effects of central oxytocin; namely positive affect, reduced physiological arousal and analgesia are also induced by c-tactile afferent (CT) stimulation.

\section{Oxytocin Facilitates Social Behaviour}


Oxytocin receptors are widely distributed throughout the brain, with dense representation within limbic forebrain regions where they co-localise with the classical neurotransmitters, allowing for oxytocin mediated modulation of a range of motivational and affective states and processes (Kendrick et al., 1997; Lee et al., 2009; Mitre et al., 2016).

In rodents, species and gender specific variation in central oxytocin receptor distribution determines several aspects of social behaviour, including pair bonding and parental care (Insel and Young, 2001; Young and Wang, 2004). For example, Insel and Shapiro (1992) found that oxytocin receptor density was significantly greater in the nucleus accumbens (NAC), prelimbic cortex, bed nucleus of the stria terminalis (BNST), midline thalamic nuclei and lateral amygdala of the monogamous prairie than the polygamous montane vole. In sensory terms, endogenous release of oxytocin is triggered by the action of mating and the presence of male olfactory chemosignals. The importance of oxytocin release in the formation of pair bonds is demonstrated by the fact female prairie voles can be induced to form partner preferences via central infusions of oxytocin in the absence of mating, while administration of an oxytocin receptor antagonist prior to mating blocks the formation of partner preferences (Cho et al., 1999; Cushing and Carter, 2000). Partner preference formation in female prairie voles has also been found to be dopamine dependent as blockade of dopamine D2 receptors in the NAC prevents oxytocin induced formation of partner bonds (Liu and Wang, 2003). Thus, it can be inferred that the significantly reduced oxytocin receptor expression in NAC of montane voles underlies their polygamous behaviour.

In terms of parental care, while virgin prairie voles show high levels of spontaneous maternal behaviour, virgin montane voles and rats ignore pups until shortly before parturition. The transition from pup avoidance to pup retrieval coincides with a significant increase in oxytocin receptor expression throughout sensory, limbic and reward related brain regions (Broad, 1999; Liu and Wang, 2003). For example, in female montane voles, postpartum oxytocin receptor expression within the lateral amygdala increases to levels comparable to prairie voles. Such changes appear to facilitate the formation of maternal motivations and infant recognition (Keverne and Curley, 2004). The first demonstration that oxytocin is critical for the expression of maternal behaviour came from studies showing that intracerebroventricualr (ICV) infusions of oxytocin induce maternal behaviours in virgin female rats (Pedersen and Prange, 1979), while in contrast ICV infusions of an oxytocin receptor antagonist delay this onset (van Leengoed, et al., 1987). In sheep too, ICV infusions of oxytocin were reported to induce rapid onset of full maternal responsivity in non-pregnant ewes as long as they were primed with 
oestrogen (Kendrick et al., 1997). Thus, there is clear evidence across species that oxytocin release in the brain promotes post-partum maternal behaviours. Indeed, individual differences in maternal sensitivity are associated with differences in oxytocin activity. For example, female rats who show high levels of maternal behaviour, defined by high levels of licking and grooming and arched-back nursing, were found to have significantly higher levels of oxytocin receptor expression in the central amygdala than those showing low levels of maternal behaviour. High licking and grooming dams also had significantly greater lactation induced oxytocin receptor expression in the BNST, MPOA and lateral septum than low licking and grooming females, highlighting the importance of oxytocin signalling in these brain regions in the regulation of maternal behaviour (Francis et al., 2000).

Both peripheral and central administration of oxytocin has been shown to have dose dependent effects on social recognition memory (Benelli et al., 1995; Popik et al., 1992; Popik and Van Ree, 1991). Ferguson et al. $(2001 ; 2000)$ showed that, despite intact olfactory function and non-social learning capability, oxytocin receptor knockout (OXKO) mice fail to recognize familiar conspecifics even after repeated interactions. The deficit is retrieved by a single, low dose, ICV infusion of oxytocin administered just before the first social encounter. Using the immediate early gene $c$-fos as a marker of neural activity the authors identified that while OTKO and control mice did not differ in the level of Fos immunoreactive cells in primary olfactory regions, only the wildtype mice showed significant levels of activation in the amygdala. Furthermore, direct infusion of oxytocin into the medial amygdala, but not the olfactory bulb, restored social recognition memory in OTKO mice. Thus, oxytocin, within the medial amygdala, is necessary for acquisition of social odour memories.

\section{Oxytocin Enhances the Salience of Socially Relevant Sensory Input} Immunohistochemistry studies have shown that oxytocin receptors are also expressed throughout primary sensory regions including the olfactory bulb (OB), primary olfactory (piriform), auditory, somatosensory and visual cortices (Mitre et al., 2016). Perhaps reflecting the importance of these brain regions for regulating maternal behaviour, such as recognition of pup vocalisations \& scents (Cohen et al., 2015; Richter et al., 2005), gender differences in oxytocin receptor expression have been reported. For example, denser receptor expression was found in the piriform cortex in female compared to male mice (Mitre et al., 2016). Development of social recognition in many mammals, including rodents, is predominantly 
dependent on olfactory cues (Wacker and Ludwig, 2012). Thus, in sensory terms the actions of oxytocin on the rodent olfactory system appears to promote the formation of social bonds such as partner preference and offspring recognition. Dluzen et al (1998) showed that direct administration of oxytocin into the $\mathrm{OB}$ lengthened retention time on a social discrimination test. This effect of oxytocin was found to be noradrenaline dependent as both 6hydroxydopamine (6-OHDA) lesions and administration of an $\alpha$-adrenergic antagonist blocked the effect. Further evidence that oxytocin release within the OB modulates noradrenaline release and may therefore facilitate the formation of offspring recognition comes from studies in sheep. For example, lesioning of a female sheep's OB, and more specifically the noradrenergic projections to the bulb, was found to disrupt formation of the maternal bond with her new lamb (Levy et al., 1995).

The actions of oxytocin on the learning and memory processes reviewed earlier lead to top down modulation of sensory responding that is also oxytocin dependent. For example Kendrick et al (1992) using electrophysiological recordings of the activity of mitral cells, the output neurones of the $\mathrm{OB}$, demonstrated that there was no preferential response to lamb odours immediately post-partum but selective responding developed over several days as recognition memory was consolidated. The medial amygdala is reciprocally connected to both the piriform cortex and OB providing a mechanism by which these top down effects can occur (Wacker and Ludwig, 2012).

More recently several studies have elegantly combined electrophysiology, optogenetics and behavioural assays to further elucidate the neural basis of oxytocin's effects on sensory processing. In a same-sex social interaction test, known to be oxytocin dependent, optogenetic activation of oxytocin neurons in the PVN lead to a significant increase in social exploration between female rats resulting in enhanced memory, with rats showing differential exploration of a novel versus familiar partner even after a 2-hour interval, by which time control rats' exploration was at chance levels (Oettl et al 2016). This effect of oxytocin was socially specific as there was no effect on object recognition. The anterior olfactory nucleus (AON) is the most anterior part of the olfactory cortex and is known to provide top down modulation of granule cells (interneurons) within the main OB. In an in-vitro model, application of an oxytocin agonist was found to increase the spontaneous excitatory activity of neurons in the AON. Furthermore, in-vivo, optogenetic activation of the PVN had the same effect, which was blocked by administration of an oxytocin receptor antagonist. Of particular note is the observation that activation of oxytocin receptors in the AON decreased the firing threshold of 
neurons, supporting the hypothesis that oxytocin release is increasing the excitability of neurons within this region.

In support of the ability of oxytocin to regulate sensory processing at its very earliest stages, direct optogenetic stimulation of neurons in the AON was found to increase excitatory inputs to granule cells which in turn inhibit mitral cells, thus showing that activation of oxytocin receptors within the $\mathrm{AON}$ can produce a transient increase in signal to noise evoked odour responses within the MOB, by inhibiting background firing. In further support of the social specificity of these findings, mice with a conditional knockout of oxytocin receptors in the AON were impaired in a social recognition test. This impairment did not reflect reduced initial interaction, demonstrating that, in social contexts, oxytocin receptors in the AON must be activated to enhance early olfactory responses to socially relevant cues (Oettl et al., 2016).

Using a social learning paradigm Choe et al (2015) reported that male mice acquired a preference for an odour previously paired with the presence of sexually receptive but not a non-receptive female. In line with the previous findings of Ferguson et al $(2001,2000)$ this learning was oxytocin dependent as administration of an oxytocin receptor antagonist abolished acquisition of odour preference. Furthermore, optogenetic stimulation of oxytocin neurons in the PVN during training on the social learning paradigm with a non-receptive female resulted in a clear preference for the female paired odour, in the absence of any nonsocially specific appetitive effects. This suggests that the activation of oxytocin neurons increased the salience of this less rewarding social cue to the level that a preference could be acquired. In agreement with previous studies showing oxytocin dependent modulation of olfactory neurons, anatomical tract tracing demonstrated that oxytocin neurons in the hypothalamus project to piriform cortex, where a dense population of oxytocin receptor expressing neurons were also identified. Using a selective knock-out of the oxytocin receptors within piriform cortex it was found that knock-out mice did not acquire a preference for the location where they had previously encountered a sexually receptive female. This finding was again socially specific and demonstrates that oxytocin receptors within the piriform cortex are needed for social odour learning. Notably these effects were not valence specific as oxytocin was also required for aversive social learning.

A recent study by Marlin et al (2015) demonstrated that the acquisition of pup retrieval behaviour by female mice is dependent on the modulatory actions of oxytocin within auditory cortex. It has previously been shown that female mice with maternal experience display higher 
signal to noise ratios in their neural responses to pup cries than virgin females within this region (Liu et al., 2006; Rothschild et al., 2013). Marlin et al (2015) demonstrated that when housed with an experienced dam and her pups, virgin female mice receiving either systemic injections of oxytocin or optogenetic stimulation within the PVN started retrieving pups significantly earlier than saline treated virgins who required at least 2 days of co-housing before they expressed retrieval behaviour. In fact, systemic or central release of oxytocin triggered retrieval in virgin dams even without cohousing. Given that pup vocalizations are the cue for dams to retrieve their pups the authors examined whether oxytocin receptor activation within left auditory cortex is necessary for the display of this behaviour. In line with the hypothesis that oxytocin release within this region is necessary for acquisition but not expression of pup retrieval, oxytocin injection or optogenetic triggered release in left auditory cortex was sufficient to stimulate retrieval in virgin females, but oxytocin receptor blockade did not disrupt retrieval in experienced females.

In contrast to rodent social behaviour, which is primarily primed by olfactory cues, humans, in common with other primates, rely more strongly on the visual domain. A range of studies in humans have shown that intranasal inhalation of oxytocin increases attention to and accuracy in discriminating visual social cues such as emotional facial expressions (Domes et al., 2013, 2010, 2007b). Eye tracking studies report that oxytocin increased the time male participants spent looking at the eye region of a presented face, perhaps providing a partial explanation for the enhanced emotion recognition observed (Andari et al., 2010; Gamer et al., 2011; Guastella et al., 2008). Consistent with an enhancement of attention to socially relevant stimuli, Leknes et al (2013)reported that, as well as sharpening participants' sensitivity to emotional facial expressions, exogenously administered oxytocin increased the pupil dilation induced by viewing these stimuli. While most studies of human social recognition have been conducted in the visual domain a recent study demonstrated that, just like in rodents, the ability of human parents to recognize their baby's cry is learned, that is sensitivity depends on amount of previous exposure (Gustafsson et al., 2013). In support of the fact this learning may be oxytocin dependent, Hollander et al (2007) found that intranasal oxytocin increased participants' sensitivity to identifying emotion from tone of voice.

Consistent with the rodent literature, neurally these changes in processing of socially relevant sensory stimuli are associated with oxytocin modulating activity within the amygdala (Domes et al., 2010, 2007a, Riem et al., 2012, 2011). For example, Domes et al (2007a) reported that inhalation of oxytocin was associated with decreased amygdala response to both implicitly 
and explicitly presented, positively and negatively valenced faces. Riem et al (2012, 2011) reported oxytocin decreased amygdala activation to infant cries, a result that was interpreted as reflecting reduced aversion. Oxytocin has also been reported to enhance functional coupling of the amygdala with fronto-cortical regions associated with affective processing and emotion regulation, such as orbitofrontal and anterior cingulate cortices (Riem et al., 2012).

Genetic studies have shown that individual variability in social behaviour is associated with single nucleotide polymorphisms (SNP) on the oxytocin receptor gene (OXTR). For example, clinically, variation in the OXTR is associated with autism and depression (LoParo and Waldman, 2014; Thompson et al., 2011) and behaviourally, SNPs been reported to account for individual differences in social skills including facial recognition memory (Skuse et al., 2014) as well as frequency of parental tactile interaction with their infant (Feldman et al., 2012). While the anatomical localisation of oxytocin receptors in humans is not currently known, in line with the rodent literature, a review by Meyer-Lindenberg and Tost (2012) reported that neurally, SNPs on the gene coding for the oxytocin receptor are associated with structural and functional changes in limbic circuitry, including the amygdala.

Further evidence that individual differences in sensitivity to socially relevant stimuli may be related to oxytocin functions comes from several recent epigenetic studies (Jack et al., 2012; Puglia et al., 2015). The first reported that DNA methylation at the OXTR was predictive of an individual's neural response to biological motion (Jack et al., 2012). Specifically, higher levels of OXTR methylation were associated with significantly higher activation of temporal parietal junction and dorsal anterior cingulate cortex - regions previously reported to support social perceptual functions (Blakemore et al., 2003; Dichter et al., 2009). Puglia et al (2015) reported that high levels of OXTR methylation were associated with increased neural activity in limbic and face processing regions when viewing angry and fearful faces. Interestingly, the authors also found that oxytocin receptor methylation moderated connectivity between the amygdala and other affective and face processing regions. Together these findings suggest that levels of OXTR methylation can influence low level sensory processing of socially relevant stimuli (Kumsta et al., 2013).

Also, in line with the animal studies reviewed earlier a number of authors report enhanced social recognition memory following intranasal oxytocin (Guastella et al., 2008; Rimmele et al., 2009; Savaskan et al., 2008). For example, Rimmele et al (2009) found that administration 
of oxytocin prior to encoding increased male participants' recognition memory, as measured by discrimination between novel and familiar faces one day later. Importantly, in parallel with earlier rodent findings, this enhanced recall was not seen for non-social stimuli.

From both human and animal studies reviewed there is evidence to show that oxytocin, both endogenously released and exogenously administered, modulates sensitivity to sensory cues across a range of modalities. Taken together, these findings indicate that oxytocin release conveys the social relevance of sensory signals, by boosting their salience, meaning they are processed preferentially. However, oxytocin's effects on sensory processing are not limited to the social domain, its release also appears to have analgesic properties decreasing sensitivity to nociceptive pain, the evidence for this will be considered in following section.

\section{The Analgesic Effects of Oxytocin}

When one considers the experience of pain it is important to distinguish between nociception defined as "the neural processes of encoding and processing an actual or potential tissuedamaging event" and pain, "an unpleasant sensory and emotional experience associated with actual or potential tissue damage" (Loeser and Treede, 2008). There are two main categories of pain: acute and chronic. Acute or nociceptive pain forms part of a rapid protective pathway that functions to minimise detected physical harm. Chronic pain may be divided into two types: inflammatory nociceptive pain, which is associated with tissue damage and its associated inflammation, and neuropathic pain which is a maladaptive response to a lesion or disease affecting the somatosensory system. The vast majority of evidence pertaining to oxytocin's analgesic properties relates to nociceptive pain.

A recent systematic review (Rash et al., 2014) showed that 29 out of 33 animal studies suggested an analgesic effect of oxytocin on acute painful stimuli delivered using electrical, thermal, mechanical and chemical stimuli. In addition, oxytocin, through effects on GABA responses in nociceptive neurons, has an analgesic effect in newborn rat pups during delivery (Mazzuca et al., 2011). There is also evidence of up-regulation of oxytocin in plasma and CNS as well as an analgesic effect in rodent models of inflammatory (Eliava et al., 2016; Matsuura et al., 2015) and neuropathic pain (Gutierrez et al., 2013).

Clinical and experimental pain investigations in humans have shown mixed results. For instance oxytocin in placebo controlled trials was shown to reduce the severity of headache 
(Wang et al., 2013) and colonic visceral perception in irritable bowel syndrome (Louvel et al., 1996) but produced no beneficial effect in fibromyalgia (Mameli et al., 2014) or pain in chronic constipation (Ohlsson et al., 2005). While oxytocin has been reported to reduce pain and unpleasantness in the cold pressor test (Rash and Campbell, 2014) and acute laser evoked thermal pain (Paloyelis et al., 2016b) other experimental pain models have not shown a clear anti-nociceptive effect (Kessner et al., 2013; Zunhammer et al., 2015). These discrepancies may relate to differences the mode of administration, dosage, the temporal dynamics of post dose testing as well as disparate trial designs and study populations (see Paloyelis et al., 2016; Tracy et al., 2015). In human studies the systemic manner of oxytocin administration makes determination of underlying mechanisms and neuroanatomical substrate difficult.

In addition to systemic release from the posterior pituitary, the projections of the oxytocin releasing magnocellular neurons of the PVN and SON to forebrain areas (e.g. NAC and amygdala) could be relevant to the observed analgesic effects (Gimpl et al., 2001). Neuroimaging studies in humans have shown that intranasal administration of oxytocin, which circumvents issues of peripherally administered hormone crossing the blood brain barrier (Tracy et al., 2015), results in increased regional cerebral blood flow in areas, such as the opercular-insula and anterior cingulate cortex, that are implicated in nociceptive processing and the pain experience (Paloyelis et al., 2016a; Treede et al., 1999).

Preclinical studies have demonstrated that parvocellular oxytocin secreting neurons in the PVN project to the spinal cord and exert a significant effect on neurons expressing oxytocin receptors in the superficial laminae (laminae I/II) of the dorsal horn (Eliava et al., 2016; Moreno-López et al., 2013; Wrobel et al., 2011). Laminae I/II of the dorsal horn is the primary target for both myelinated and unmyelinated afferent fibres that respond to noxious stimulation in the periphery (although it is of note that thinly myelinated and unmyelinated fibres that signal the presence of innocuous mechanical and thermal stimuli also project to these same laminae) (Craig, 2002).

A recent elegant study demonstrated, in rodents, the existence of a group of approximately 30 oxytocin secreting parvocelluar neurons in PVN that have a bipolar spindle appearance and project to both magnocellular oxytocin secreting cells in the SON as well as the superficial laminae of the dorsal horn of the spinal cord (Eliava et al., 2016). Through release of oxytocin this descending projection inhibited C-fibre discharges induced by noxious range hind paw stimulation in superficial laminae wide dynamic range neurons expressing neurokinin 1 
receptors. This effect was blocked by oxytocin receptor blockade. Oxytocin has also been shown to inhibit neuronal responses in lamina II wide dynamic range neurons in the rodent spinal ligation neuropathic pain model (Condés-Lara et al., 2005). Intriguingly activity of Clow threshold mechanosensitve afferents (C-LTMs) is integrated with that of nociceptors in lamina I wide dynamic range neurons (Andrew, 2010), the relevance of which will become apparent later. In models of nociceptive and inflammatory pain increased oxytocin expression and evidence of neuronal activation is seen in parvocellular PVN (Matsuura et al., 2016, 2015). Optogenetic activation of parvocellular PVN oxytocin secreting neurons also resulted in analgesia in inflammatory although not neuropathic rodent pain models (Eliava et al., 2016). Other studies have suggested that oxytocin's analgesic effects are mediated by presynaptic enhancement of GABA inhibitory interneurons in laminae I/II (Condés-Lara et al., 2009; Jo et al., 1998) or through engagement of endogenous pro-analgesic opioid and cannabinoid systems (Russo et al., 2012).

Oxytocin receptors are also present in spinal dorsal root ganglia on nociceptor C-fibre cell bodies (Moreno-López et al., 2013) where they co-localise with neural nitrous oxide synthase (Gong et al., 2015). Dorsal root ganglia cells are blood brain barrier free and potentially susceptible to the effects of circulating oxytocin (Tracy et al., 2015). Acting through a pathway involving nitrous oxide, oxytocin leads to a reduction in excitability of capsaicin sensitive nociceptors (Gong et al., 2015). There is evidence that oxytocin also acts through the vasopressin, V1A receptor in primary sensory neurons (Qiu et al., 2014). Interestingly activation of parvocellular PVN oxytocin secreting neurons, in addition to acting by a descending spinal pathway, also results its systemic release from the posterior pituitary by virtue of its parallel projection to the SON (Eliava et al., 2016).

Thus oxytocin's analgesia promoting effects may result from coordinated inhibition of nociceptive input acting both directly and indirectly via descending neural pathways to the spinal cord dorsal horn and circulating hormone respectively. In support of this a recent study in humans showed that intranasal administration of oxytocin not only attenuates perceived pain intensity of the pricking sensation associated with laser induced heat but also the N1 component of the laser evoked cortical potential, which is thought to reflect the magnitude of A $\delta$ nociceptive input to the contralateral S1 and opercular-insular cortex (Paloyelis et al., 2016b). 
Whilst there has been much focus on direct neural, in particular spinal, mechanisms for the observed pro-analgesic effects one would expect a highly complex relationship between oxytocin and the various biopsychosocial factors that impact on the experience of pain (see Tracy et al., 2015). For example, it is known that social support can affect the pain experience, an effect that is potentially modulated by oxytocin (Krahé et al., 2013). In addition oxytocin modulates the stress response (Ditzen et al., 2007; Rash et al., 2014; Tracy et al., 2015) which may also influence the experience of pain (Tracy et al., 2015). In the following section we consider the evidence that oxytocin release, specifically triggered by the stimulation of sensory nerves in the skin, may also underpin many of these beneficial effects of social interaction on health and well-being.

\section{Cutaneous Stimulation Induces Oxytocin Release}

From the evidence reviewed thus far it is clear that oxytocin release occurs in response to sensory stimuli of various modalities, both appetitive and aversive, and that through its actions on the CNS it can facilitate social behaviour in a contextually specific manner. Activation of sensory nerves in the skin can also trigger oxytocin release and it was argued in a recent review article that its release in response to such low intensity cutaneous stimulation is of particular importance to its hypothesised role in reducing stress and promoting wellbeing (UvnäsMoberg et al., 2014). Peripherally, for example, plasma oxytocin levels were significantly increased by 1 minute of gentle stroking touch applied to the back of unconscious male adult rats (Stock and Uvnäs-Moberg, 1988). Abdominal stroking of conscious dogs without any social reinforcement such as vocal encouragement or eye contact, increased urinary oxytocin levels (Mitsui et al., 2011). In humans, massage-like hand movements applied by new-born babies to their mother's breast increases maternal plasma oxytocin levels (Matthiesen et al., 2001). Additionally, 15 minutes of moderate pressure Swedish massage significantly increases plasma oxytocin levels in both men and women (Morhenn et al., 2012). In women, a significant increase in plasma oxytocin was identified after 10 minutes of warm partner contact (Grewen et al., 2005).

Centrally, immunohistochemical studies have identified stroking touch applied to the anogenital region of 7 day old rabbit pups and 10 day old rat pups activates oxytocin neurones of the hypothalamus, particularly in the PVN (Caba et al., 2003; Lenz and Sengelaub, 2010). Both slowly stroking the back and simply holding young rats for 5 minutes led to significantly more $50-\mathrm{kHz}$ vocalisations, associated with positive affect, than $22-\mathrm{kHz}$ negative 
vocalisations. However, only dynamic stroking touch significantly increased the number of active oxytocin neurons in the PVN (Okabe et al., 2015).

Physiologically, blood pressure and heart rate was reduced by 5 minutes of stroking touch applied at a velocity of $\sim 20 \mathrm{~cm} / \mathrm{s}$ to both the back and abdomen of adult male rats in comparison to a no stroking control condition (Lund et al., 1999). Supporting a mediating role for oxytocin in the observed effects, exogenous administration to adult rats both peripherally (subcutaneously) and centrally (ICV) for 5 consecutive days significantly reduced blood pressure compared to saline treated controls (Petersson et al., 1997). These findings are further supported by the results of a study conducted by Holst et al (2002) on male rats where either abdominal stroking at a velocity of $\sim 20 \mathrm{~cm} / \mathrm{s}$ for 5 minutes per day with a soft brush on postnatal days (PNDs) 1-7 or daily exogenous oxytocin administration on PNDs 1-14, significantly reduced diastolic blood pressure in adulthood. In humans, frequency of partner hugs and massage, but not kissing, hand-holding or sitting/lying close, positively correlated with basal plasma oxytocin levels, which were negatively correlated with resting blood pressure and heart rate (Light et al., 2005).

Of relevance to the earlier discussion of the analgesic effects of oxytocin, both massage-like abdominal stroking of adult male rats for 30-45 seconds and exogenous oxytocin administration produced an analgesic effect, as determined by increased hot plate withdrawal latency, which was inhibited by oxytocin antagonist administration (Agren et al., 1995). The analgesic effect of massage-like stroking was also demonstrated by Lund et al., (2002) where adult male rats receiving 5-10 minutes of abdominal stroking at a velocity of $\sim 20 \mathrm{~cm} / \mathrm{s}$ every other day for 14 treatments showed a significant positive correlation between number of treatments and heat and mechanical hindpaw withdrawal latencies (HWLs), whereas control rats who were held but not stroked showed no HWL changes. Plasma and periaqueductal gray (PAG) oxytocin levels were found to be significantly greater than controls following 14 and 12 stroking treatments respectively. Additionally, oxytocin injection into the PAG increased mechanical and heat HWLs compared to saline treated controls, but this effect was attenuated by administration of the nonspecific opioid receptor antagonist naloxone and specific $\mu$ - and $\kappa$-opioid receptor antagonists. Thus, the analgesic effects of stroking touch appear to involve an oxytocin mediated effect on $\mu$ - and $\kappa$-opioid receptor activation in the PAG. 
Oxytocin release induced by low intensity cutaneous stimulation also has behavioural effects. In adult male rats, 5 or 10 minutes of abdominal stroking at a velocity of $\sim 20 \mathrm{~cm} / \mathrm{s}$ had a sedative effect, decreasing locomotor and rearing activity in an open field test, in comparison to a control group that were handled but not stroked (Uvnäs-Moberg et al., 1996). This effect was comparable to that produced by administration of high doses of exogenous oxytocin, whereas low doses of oxytocin have an anxiolytic rather than sedative effect, increasing central compared to peripheral locomotion in an open field test (Uvnäs-Moberg et al., 1994, 1992). These anxiolytic effects may be due to modulatory effects of oxytocin on the HPA axis. Application of an oxytocin antagonist to the PVN led to increased basal adrenocorticotropic hormone (ACTH) levels, but reduced ACTH in response to forced swimming, suggesting oxytocin inhibits HPA activity at rest, but increases HPA activity during stressors (Neumann et al., 2000). Similarly, subcutaneous oxytocin administration in rats produced a transient increase in $\mathrm{ACTH}$ and corticosterone, but a significant decrease in corticosterone but not ACTH 6 hours later, while oxytocin administration once per day for 5 days decreased corticosterone levels. Thus, oxytocin appears to stimulate the HPA axis in the short term, but inhibit it in the long-term (Petersson et al., 1999). Additionally, oxytocin administered to the locus coerulueus (LC) of adult rats was found to increase the responsiveness $\alpha_{2}$-adrenoreceptors, which inhibit noradrenergic neurons, providing a mechanism by which oxytocin inhibits stress responses (Petersson et al., 1998). Other beneficial effects of repeated exogenous oxytocin administration identified in rats are increased weight gain (Uvnäs-Moberg et al., 1996; Uvnas-Moberg et al., 1998), improved learning due to oxytocin reducing corticosterone levels (Uvnäs-Moberg et al., 2000) and increased social interactions, particularly increased duration of physical contact (Witt et al., 1992).

In specific support of the developmental significance of touch, a number of studies have shown neonatal tactile stimulation (NTS) can prevent the negative behavioural effects seen in adulthood following neonatal isolation (NI) (Imanaka et al., 2008; Muhammad et al., 2011; Wei et al., 2013). For example, in a study of male mandarin voles conducted by Wei et al (2013), NTS consisted of 15 minutes of soft brush stroking dorsally from head to tail during 3 hours of NI per day on PNDs 1-13. A control group were handled daily, but otherwise left with the dam undisturbed. NI pups weighed significantly less than controls on PNDs 4-16, whereas NTS pups were comparable to controls. In adulthood, NI voles showed increased anxiety like behaviour, spending less time in the centre of an open field, reduced object recognition and engaged in less body contact with another vole during a social interaction test 
whereas the behaviour of NTS voles were comparable to controls. Additionally, at PND 4-16 and as adults, NI adult voles had significantly higher plasma corticosterone levels, whereas again NTS levels were comparable to controls. Indicating that early tactile stimulation impacts the developing brain, as adults NI voles had significantly fewer oxytocinergic neurons in the PVN, while voles receiving NTS showed comparable numbers to controls. A similar study on rats, but with NI for 1 hour per day on PNDs 1-9 and NTS consisting of gently handling dorsally from head to tail for 5 minutes per day, reported that, in comparison to NIs, NTS rats showed increased exploratory behaviour in an open field test, reduced anxiety in an elevated plus maze, increased HWL on a hot plate test and in females, reduced freezing time in a contextual fear conditioning test (Imanaka et al., 2008). Muhammad et al (2011) also found NTS, in the form of stroking with a soft feather duster while huddled together with another pup on a warming pad at $34^{\circ} \mathrm{C}$ for 15 minutes, 3 times per day on PNDs 2-21, led to NTS female rats, as juveniles, displaying less anxiety behaviour on the elevated plus maze and males showing decreased play fighting behaviour compared to controls who underwent maternal separation but received no tactile stimulation.

As described above, oxytocin has anxiolytic effects, can increase weight gain, alters pain responses, improves learning and modulates HPA activity and social behaviour. These studies also highlight the adverse effects of NI or maternal separation on later life behaviour can be prevented by tactile stimulation, mediated, at least in part by the central release of oxytocin triggered by stimulation of cutaneous nerves. To date, little attention has been paid to the specific identity of the sensory nerves underlying these effects (though see Uvnäs-Moberg et al., 2014; Walker and McGlone, 2013). In the following section we make the case that a specific class of unmyelinated low threshold mechanoreceptor found only in the hairy skin of mammals has exactly the response characteristics, neural projections, physiological and behavioural effects to be the most likely candidate.

\section{Are C-Tactile Afferents the sensory nerves mediating the physiological and behavioural effects of cutaneous stimulation?}

The skin senses serve both a discriminative function, allowing us to manipulate objects, detect touch and temperature, plus an emotional one, manifested as perceptions of itch and pain. Different classes of cutaneous nerve fibre sub-serve these dissociable aspects of somatosensation: large diameter, myelinated $\mathrm{A} \beta$ afferent fibres rapidly convey information about the nature and location of touch to somatosensory cortex, triggering rapid action; 
whereas small diameter, slowly conducting $\mathrm{A} \delta$ and c-fibres project via an anatomically and functionally distinct interoceptive pathway signalling affective (rather than sensing) states (McGlone et al., 2014). While the role of c-fibres in signalling nociception, temperature and itch is well established, an affective emotional role for touch has only more recently been recognized with the identification and characterisation of a class of nerve fibres named CTs (Vallbo et al., 1999).

CTs are stimulus selective, temperature and velocity tuned, showing their highest firing frequency responses to an innocuous skin temperature stimulus moving with low force and velocity (1-10 cm/second) (Ackerley et al., 2014; Löken et al., 2009). Importantly, when participants are asked to make subjective ratings of their tactile experience, the stimulus speed at which CTs fire most strongly also produces the highest subjective ratings of pleasantness (Essick et al., 1999; Löken et al., 2009). Indeed, the relationship between CT firing frequency, as well as subjective liking of touch, and different velocities of stroking are described by an inverted $U$ response function. As can be seen in Figure 1, this contrasts with slowly adapting myelinated mechano-afferents where a linear relationship between firing frequency and stroking velocity is observed.
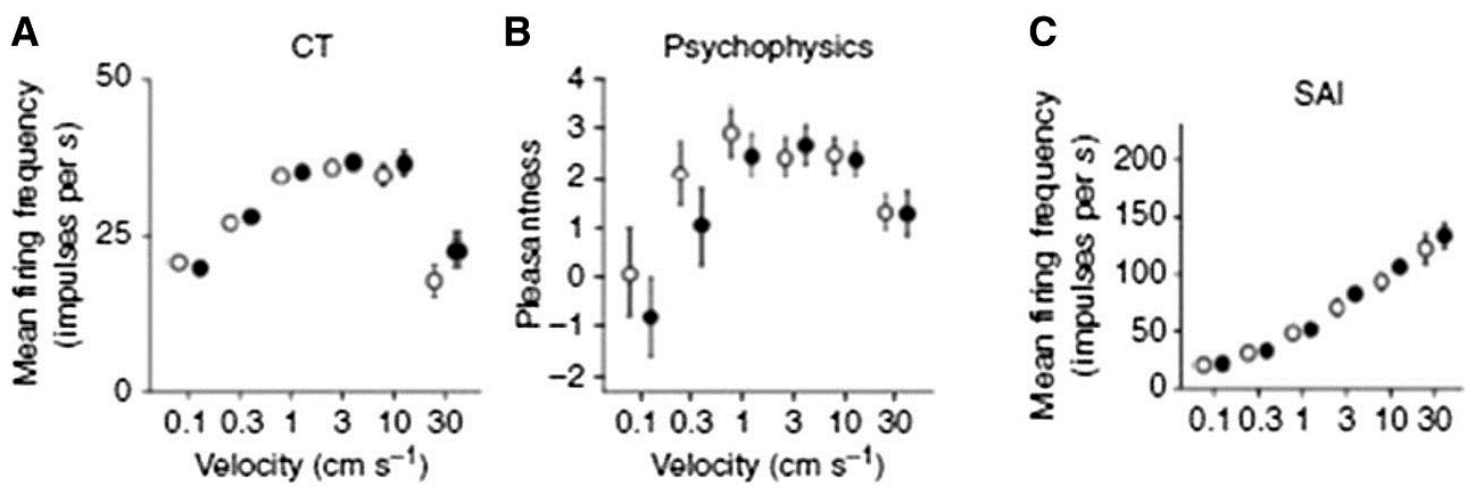

Figure 1. Brush Stimulation and Nerve Recordings. (A and C) Dots show average discharge rates during brush stroking for the two types of mechanoafferents depicted here that were explored with the full range of stimulus velocities (C-tactile, $n=16, A ; S A I, n=8, C)$. Note that scaling on the $y$ axes is different for C-tactile and myelinated afferents. (B) Average ratings of perceived pleasantness in response to soft brush stroking. Data are from ten subjects. Error bars indicate SEM. Open circles $=0.2 \mathrm{~N}$ Force, Closed circles $=0.4 \mathrm{~N}$ Force. Figure is from Löken et al 2009.

Neuroimaging studies in neuronopathy patients who lack $A \beta$ fibres and healthy controls have shown that gentle stroking touch, applied to hairy skin (where CTs are abundant), but not 
palmar skin (where CTs have not been found), reliably produces activation in posterior insular (interoceptive) as well as somatosensory cortex (McGlone et al., 2012; Olausson et al., 2002). Here, in common with other c-fibre mediated thermal, painful and pruritic inputs, they are thought to contribute to the central representation of the physical condition of the body (Björnsdotter et al., 2010).

The "Social Touch Hypothesis" proposes that CTs provide a neurobiological substrate for intimate social behaviour. The response characteristics of CTs suggest they are highly sensitive to the type of stimulus that occurs in affiliative tactile interactions (Morrison et al., 2010). Thus, in homeostatic terms CT activating touch has gained its innate rewarding value by virtue of the fact it signals proximity of others. In direct support of the Social Touch Hypothesis, a recent observational study measured how participants interacted with either their partner or infant, versus an artificial arm (Croy et al., 2016). Non-social stroking of the artificial arm "in a way the person would like it" was recorded at a broad range of velocities that on average (at $19.4 \mathrm{~cm} / \mathrm{sec}$ ) fell outside the CT optimal range. In contrast, in both social touch conditions velocities used to caress their partner (average $3.2 \mathrm{~cm} / \mathrm{sec}$ ) or infant (average $8.4 \mathrm{~cm} / \mathrm{sec}$ ) spontaneously fell within the CT optimal range of between $1-10 \mathrm{~cm} / \mathrm{sec}$.

Physiologically, in times of stress, social touch decreases heart rate, blood pressure and cortisol release in humans and other mammals (Walker and McGlone, 2013). For example, young rhesus monkeys who receive nurturing physical contact from their mother, following exposure to a stressor, showed a more rapid decline in autonomic and endocrine activity than those who do not receive this contact comfort (Parker et al., 2006). In human infants, parental touch is a key regulator of physiological and behavioural arousal (Hofer, 1994); babies that received skin-to-skin contact with a carer during a medical procedure showed fewer signs of distress and arousal than children wrapped in swaddling (Vannorsdall et al., 2004). Also, in adults, supportive physical contact from a spouse or partner has been shown to modulate physiological responses to an acute stressor significantly more than verbal support (Ditzen et al., 2007). Thus, affiliative social behaviours, involving tactile interactions, exert stress attenuating effects in humans and other mammals.

However, in none of these studies has attention been paid to the neurobiological mechanisms underlying the beneficial consequences of touch. Yet, there is a good deal of evidence that the specific quality of touch received impacts its stress attenuating efficacy and it is gentle dynamic touch which is most effective (Walker and McGlone, 2013). For example, in rats, 
maternal arch-back licking and grooming has a moderating effect on pups' stress responsivity (Caldji et al., 1998; Champagne et al., 2003) and in the absence of this maternal input, the beneficial effects are mimicked by stroking with a soft brush, (Kuhn et al., 1990; van Oers et al., 1998) a stimulus that has been shown to reliably activate CTs. In human infants too, gentle stroking elicits greater positive emotions than static touch or handling associated with noninvasive medical procedures (Field, 1980). Indeed, a recent study reported specifically that CT optimal velocity touch reduced infants' heart rates to a significantly greater degree than faster or slower bouts of stroking (Fairhurst et al., 2014). Mirroring the effects of endogenously administered oxytocin (Leknes et al., 2013), social touch designed to optimally activate CTs elicited significantly greater pupillary dilation, indicative of attentional orienting, than $\mathrm{A} \beta$ targeted machine touch (Ellingsen et al., 2014).

In humans, evidence for the specific rewarding value of $\mathrm{CT}$ activating touch comes from a range of fMRI studies which consistently shown that gentle stroking applied to hairy but not palmar skin at CT optimal velocity, reliably produces neural activation in affective and reward related brain regions (Gordon et al., 2013; McGlone et al., 2012; Olausson et al., 2002; Trotter et al., 2016). These areas form key nodes of neural networks with an established role in guiding aspects of social perception, cognition and behaviour (Adolphs, 2003). Further evidence for the specific rewarding value of CLTM (CTs in animals) activation comes from several recent rodent experiments. Firstly Maruyama et al (2012) used microdialysis to directly measure dopamine release in the NAC in response to gentle stroking touch applied to the back, limbs or abdomen. The stroking was applied CT optimally at a velocity of approximately $5 \mathrm{~cm} / \mathrm{sec}$. In contrast to a noxious pinching stimulus in the same locations, stroking at all sites produced a significant increase in dopamine release in both awake and anesthetized rats. The effect was lateralized with stroking on one side of the back leading to NAC dopamine release on the contralateral side of the brain. Intriguingly the highest levels of dopamine release were measured in response to stroking on the back. Given a molecular genetic visualization study identified a population of CLTMs in mice that are activated by stroking, but not noxious mechanical touch, and are more densely distributed in dorsal than ventral thoracic sites, with greater proximal than distal limb innervation, (Liu et al., 2007) adds further support to the notion that evoked dopamine release is a response to the specific activation of these cutaneous afferents. Furthermore, activation of unmyelinated sensory nerves, which respond preferentially to massage like stroking, was found to promote the formation of conditioned place preference, indicating their activation carries a positively reinforcing value (Vrontou et al., 2013). 
Taken together, the studies reviewed on the cutaneous stimulation of oxytocin release and those characterising the response properties, behavioural and physiological consequences of CT activating touch suggest that these low threshold mechanoreceptors may be key mediators of oxytocin release during affiliative tactile interactions. Of particular relevance is the recent finding by Okabe et al (2015) showing selective activation of oxytocinergic neurons in the PVN, following 5 minutes of CT targeted stroking touch. In addition, while the tactile stimuli delivered in the massage studies reviewed vary in terms of the velocity and force they were applied with, we have recently shown that 5 minutes of CT targeted stroking $(5 \mathrm{~cm} / \mathrm{sec}-$ low force), applied to the back of rats, significantly reduced their subsequent activity in an open field (unpublished observation see Figure 2). This finding is entirely consistent with those previously reported by Uvnäs-Moberg et al $(1996$; 1994) which found that both a more rapid and forceful abdominal massage or high doses of exogenously administered oxytocin had the same sedative effects on behaviour. Though studies combining direct measurement of oxytocin release triggered by $\mathrm{CT}$ activating touch with behavioural and physiological indices of arousal are required, a CT optimal stimulus appears sufficient to illicit the relaxing behavioural effects associated with oxytocin release triggered by cutaneous stimulation of the skin.

a)

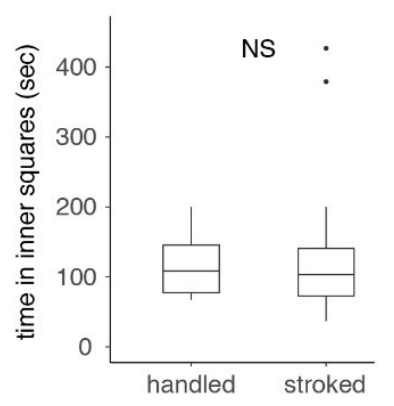

b)

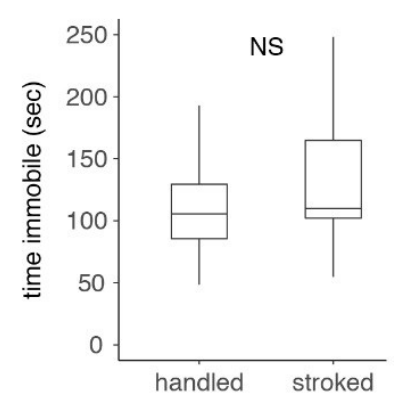

c)

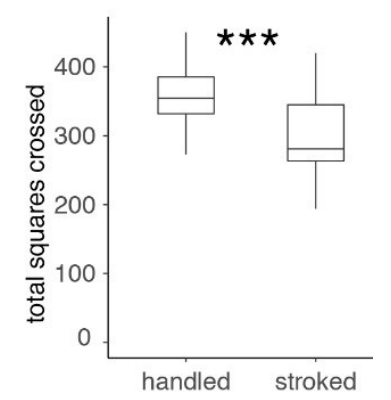

Figure 1. Box and whisker plots (medians, IQR, $1.5 \times$ IQR) showing differences in behaviour in the open field of rats that were handled or stroked for five minutes prior to testing: a) time spent in the inner squares, b) time immobile, c) total number of squares crossed. $N=14$ per group, $z=6.23, p<0.001$

Having said this, it is important to note that the low intensity cutaneous stimulation associated with the release of oxytocin will result in the activation of all classes of cutaneous low threshold mechanosensitive afferent fibres. As well as CTs D-hair afferents have response properties that are 
similar to those associated with oxytocin release. D-hair afferent fibres, which are A $\delta$ fibres with intermediate conduction velocities, are associated with down hairs of the cat and innervate all awl/auchene and zigzag hairs in rodents ( $\mathrm{Li}$ et al., 2011). They are rapidly adapting receptors that fire in response to hair movement (Lechner and Lewin, 2013; Li et al., 2011). D-hair afferents are exquisitely sensitive to low mechanical forces and indeed respond vigorously to slow ramp stimuli, significantly more vigorously at such velocities than $\mathrm{A} \beta$ fibres innervating hair follicles (Brown and Iggo, 1967; Lechner and Lewin, 2013; Milenkovic et al., 2008). Thus, stroking stimuli at low and intermediate velocities will preferentially activate both CTs (C-LTMs) and low threshold A $\delta$ hair afferents. However, similar to $A \beta$ afferent fibres that innervate hairy skin, the firing of rates of $A \delta$ hair afferents increase with increasing velocity of the applied stimulus and do not show the classical velocity inverted-U shaped firing properties exhibited by CTs (Lechner and Lewin, 2013; Löken et al., 2009; Milenkovic et al., 2008). Furthermore, although low threshold A $\delta$ fibres have been reported in human hairy skin their properties have not been extensively investigated and the existence of Dhairs in humans is therefore uncertain (Adriaensen et al., 1983).

\section{C-Tactile Afferents Inhibit Pain}

While the relief perceived by touching a sore body part is well recognised in everyday life, the mechanisms underlying touch's apparently analgesic effect are largely unknown. Studies in animal models and in humans have focused primarily on spinal and supra spinal mechanisms respectively (Inui et al., 2006; Salter and Henry, 1990). Recently, Mancini et al (2015) reported that a tactile stimulus significantly reduced both early $\mathrm{A} \delta$ and late C-fibre evoked potentials. Furthermore, brain stem generated eye blink reflexes were also reduced, leading the authors to conclude that the analgesic effect of touch is most likely mediated by subcortical gating of ascending nociceptive inputs (Mancini et al., 2015). While the tactile stimulus delivered in this study was optimised for activation of discriminative $A \beta$ afferents, several recent animal studies have indicated specific activation of CLTMs also has analgesic effects. For example, Lu and Perl (2003) using whole cell recording in rat spinal cord slices provided evidence of a role for CLTMs in inhibiting c-nociceptive inputs to the dorsal horn. The authors identified a monosynaptic inhibitory connection between two different types of neuron located within the mid portion of the spinal substantia gelatinosa. The fact that the presynaptic cell in the pairs consistently showed lower thresholds and slower dorsal root evoked excitatory post synaptic potentials (EPSPs) than the postsynaptic neuron was consistent with the notion that the dorsal root excitation was associated with relatively large diameter rapidly conducting C-LTMs while the postsynaptic cell 
was in receipt of c-nociceptive inputs ( $\mathrm{Lu}$ and Perl, 2003). Further support for the notion that CLTM inputs can supress nociceptive impulses comes from the observation that administration of TAFA4, a chemokine protein and specific marker on C-LTMs, reduced inflammation induced mechanical hypersensitivity (Delfini et al., 2013). In contrast, TAFA4 knockout mice displayed enhanced mechanical hypersensitivity following inflammation or injury which could be reversed by administration of TAFA4 protein into the spinal cord (Delfini et al., 2013). Taken together these findings are consistent with an analgesic role for C-LTMs via their modulation of nociceptive inputs to the spinal cord. An analgesic effect of CT stimulation has also been reported in humans, where brushing the skin at a CT optimal velocity either prior to or contiguously with delivery of a heat pain stimulus significantly reduced perceived pain intensity. This effect was CT specific as both $A \beta$ targeted vibration and faster stroking were less effective (Liljencrantz, 2014).

While under normal healthy conditions CTs (CLTMs) function to signal touch pleasantness and inhibit pain, under pathological pain conditions their function appears to be lost. Tactile allodynia is a symptom of neuropathic pain conditions in which typically innocuous light touch elicits a noxious sensation. Thus a CTs' preferred stimulus that is typically reported as pleasant becomes aversive, indicating a loss of their apparent analgesic properties. Recently a number of studies have indicated CLTMs are directly involved in allodynia. For example, Seal et al (2009) created a mouse knockout model which functionally silenced CLTMs, by the removal of the vesicular glutamate transporter (VGLUT3) from these primary afferents thus preventing their excitatory input to the spinal cord. Suggestive of a critical role of CLTMs in tactile allodynia, loss of VGLUT3 was found to significantly reduce mechanical hyperactivity to innocuous stimuli in models of chronic inflammatory, neuropathic and post-surgical pain.

In addition to these initial findings in rodent models several studies, using experimental models of tactile allodynia in human subjects have added support to the notion that under pathological conditions CTs no longer signal touch pleasantness or inhibit pain but rather their activation induces painful sensations.

The classical view is that tactile allodynia is mediated by a change in the signalling within the spinal cord as a result of central sensitization which allows A $\beta$ LTMs to activate nociceptive neurons. Consistent with this canonical view that tactile allodynia is causally associated with activation of large diameter, rapidly conducting, tactile afferents, compression or ischemic block has been reported to abolish allodynia. However other studies have reported continued allodynia following large fibre blockade, but relief by local anaesthetization of c-fibers in patients 
experiencing ongoing pain. Using a novel 'two-compartment model' of allodynia Nagi et al (2011) induced pain by infusion of hypertonic saline into the tibialis anterior muscle, whereas the neutral stimulus (vibration or gentle stroking) was applied to the overlying skin, physically separated from the muscle below by the underlying fascia. The authors found that both vibration and brushing evoked allodynia was dependent upon the functioning of unmyelinated cutaneous afferents, but persisted during blockade of myelinated fibers. In another study, using a heat / capsaicin model, Liljencrantz et al (2013) were able to effectively induce tactile allodynia in a group of neurologically healthy subjects but not in two neuronopathy patients lacking A $\beta$ afferents. However, using a 2 alternative forced choice task, the two patients did reliably report reduced sensation of $\mathrm{CT}$ activating touch in the allodynic versus an untreated control zone. In addition, fMRI in both an $\mathrm{A} \beta$ dennervated patient and the control participants showed significantly altered processing of CT activating touch in the posterior insula cortex - the primary cortical area for c-tactile processing - when applied to the capsaicin treated versus control zone. This suggests that there has been a change in the central processing of the CT signal. While the lack of pain in the neuronopathy patients indicates some role for $A \beta$ afferents in allodynic pain, the fact both their perceptual and neural responses changed is further evidence that CT afferent signals are also affected. This assertion is supported by a further study using the same capsaicin model in healthy participants which found decreases in tactile direction discrimination and reduced pleasantness ratings - measures of $\mathrm{A} \beta$ and CT function respectively (Liljencrantz et al., 2014). In the allodynic zone, reported pleasantness ratings of CT optimal velocity stroking were reduced to the level of $A \beta$ targeted stroking.

Taken together, the results of these studies suggest that rather than evoking the painful percept per se, in the presence of allodynia CT inputs are suppressed (Liljencrantz and Olausson, 2014). Evidence to date suggests that CT afferents, under normal conditions, signal via the spino thalamic tract. In neuropathic pain this input may be gated, functionally allowing for the prioritization if nociceptive input from the periphery, leading to the observed decrease in perceived touch pleasantness (Andrew, 2010).

\section{Conclusion}

In conclusion, data collected to date and reviewed here has shown that cutaneous stimulation directly targeted to optimally activate CTs reduces physiological arousal, carries a positive affective value and, under healthy conditions, inhibits responses to painful stimuli. These effects mirror those reported following endogenous release and exogenous administration of oxytocin, 
suggesting that activation of CTs triggers oxytocin release. While direct tests of this assertion are still required the available data supports the hypothesis the CT system provides a neurobiological basis for the formation and maintenance of social bonds.

Funding Sources: McGlone \& Walker are currently funded by a Leverhulme Trust project grant RPG-2013-058 which employs Trotter. Marshall is in receipt of a PhD studentship jointly funded by LJMU and Salford NHS Trust. 


\section{References:}

Ackerley, R., Backlund Wasling, H., Liljencrantz, J., Olausson, H., Johnson, R.D., Wessberg, J., 2014. Human C-Tactile Afferents Are Tuned to the Temperature of a Skin-Stroking Caress. J. Neurosci. 34, 2879-2883. doi:10.1523/JNEUROSCI.2847-13.2014

Adolphs, R., 2003. Cognitive neuroscience of human social behaviour. Nat.Rev.Neurosci. 4, 165178. doi:10.1038/nrn1056

Adriaensen, H., Gybels, J., Handwerker, H.O., Van Hees, J., 1983. Response properties of thin myelinated (A-delta) fibers in human skin nerves. J. Neurophysiol. 49, 111-122.

Agren, G., Lundeberg, T., Uvnäs-Moberg, K., Sato, A., 1995. The oxytocin antagonist 1-deamino2-d-Tyr-(Oet)-4-Thr-8-Orn-oxytocin reverses the increase in the withdrawal response latency to thermal, but not mechanical nociceptive stimuli following oxytocin administration or massage-like stroking in rats. Neurosci. Lett. 187, 49-52. doi:10.1016/0304-3940(95)11335-T

Andari, E., Duhamel, J.-R., Zalla, T., Herbrecht, E., Leboyer, M., Sirigua, A., 2010. Promoting social behavior with oxytocin in high-functioning autism spectrum disorders. PNAS Proc. Natl. Acad. Sci. United States Am. 107, 4389-4394. doi:10.1073/pnas.0910249107

Andrew, D., 2010. Quantitative characterization of low-threshold mechanoreceptor inputs to lamina I spinoparabrachial neurons in the rat. J. Physiol. 588, 117-124.

doi:10.1113/jphysiol.2009.181511

Benelli, A., Bertolini, A., Poggioli, R., Menozzi, B., Basaglia, R., Arletti, R., 1995. Polymodal dose-response curve for oxytocin in the social recognition test. Neuropeptides 28, 251-255. doi:10.1016/0143-4179(95)90029-2

Björnsdotter, M., Morrison, I., Olausson, H., 2010. Feeling good: On the role of C fiber mediated touch in interoception. Exp. Brain Res. 207, 149-155. doi:10.1007/s00221-010-2408-y

Blakemore, S., Boyer, P., Meltzoff, A, 2003. The Detection of Contingency and Animacy from Simple Animations in the Human Brain 837-844. doi:10.1093/cercor/13.8.837

Broad, K.D., 1999. Previous maternal experience potentiates the effect of parturition on oxytocin receptor mRNA expression in the paraventricular nucleus. Eur. J. Neurosci. 11, 3725-3737. doi:10.1046/j.1460-9568.1999.00782.x

Brown, A.G., Iggo, A., 1967. A quantitiative study of cutaneous receptors and afferent fibres in cat and rabbit. J. Physiol. 193, 707-733.

Caba, M., Rovirosa, M.J., Silver, R., 2003. Suckling and genital stroking induces Fos expression in hypothalamic oxytocinergic neurons of rabbit pups. Dev. Brain Res. 143, 119-128. doi:10.1016/S0165-3806(03)00064-6

Caldji, C., Tannenbaum, B., Sharma, S., Francis, D., Plotsky, P.M., Meaney, M.J., 1998. Maternal care during infancy regulates the development of neural systems mediating the expression of fearfulness in the rat. Proc. Natl. Acad. Sci. U. S. A. 95, 5335-5340.

doi:10.1073/pnas.95.9.5335 
Champagne, F. A., Francis, D.D., Mar, A., Meaney, M.J., 2003. Variations in maternal care in the rat as a mediating influence for the effects of environment on development. Physiol. Behav. 79, 359-371. doi:10.1016/S0031-9384(03)00149-5

Charpak, S., Armstrong, W.E., Muhlethaler, M., Dreifuss, J.J., 1984. Stimulatory action of oxytocin on neurones of the dorsal motor nucleus of the vagus nerve. Brain Res. 300, 83-89. doi:10.1016/0006-8993(84)91342-8

Cho, M.M., DeVries, a. C., Williams, J.R., Carter, C.S., 1999. The effects of oxytocin and vasopressin on partner preferences in male and female prairie voles (Microtus ochrogaster). Behav. Neurosci. 113, 1071-1079. doi:10.1037/0735-7044.113.5.1071

Choe, H.K., Reed, M.D., Benavidez, N., Montgomery, D., Soares, N., Yim, Y.S., Choi, G.B., 2015. Oxytocin Mediates Entrainment of Sensory Stimuli to Social Cues of Opposing Valence. Neuron 87, 152-163. doi:10.1016/j.neuron.2015.06.022

Cohen, Y., Putrino, D., Wilson, D.A., 2015. Dynamic cortical lateralization during olfactory discrimination learning. J Physiol 7, 1701-1714. doi:10.1113/jphysiol.2014.288381

Condés-Lara, M., Maie, I.A.S., Dickenson, A.H., 2005. Oxytocin actions on afferent evoked spinal cord neuronal activities in neuropathic but not in normal rats. Brain Res. 1045, 124-133. doi:10.1016/j.brainres.2005.03.020

Condés-Lara, M., Rojas-Piloni, G., Martínez-Lorenzana, G., López-Hidalgo, M., RodríguezJiménez, J., 2009. Hypothalamospinal oxytocinergic antinociception is mediated by GABAergic and opiate neurons that reduce A-delta and C fiber primary afferent excitation of spinal cord cells. Brain Res. 1247, 38-49. doi:10.1016/j.brainres.2008.10.030

Craig, A.D., 2002. How do you feel? Interoception: the sense of the physiological condition of the body. Nat. Rev. Neurosci. 3, 655-666. doi:10.1038/nrn894

Croy, I., Luong, a., Triscoli, C., Hofmann, E., Olausson, H., Sailer, U., 2016. Interpersonal stroking touch is targeted to C tactile afferent activation. Behav. Brain Res. 297, 37-40. doi:10.1016/j.bbr.2015.09.038

Cushing, B.S., Carter, C.S., 2000. Peripheral pulses of oxytocin increase partner preferences in female, but not male, prairie voles. Horm. Behav. 37, 49-56. doi:10.1006/hbeh.1999.1558

Delfini, M.C., Mantilleri, A., Gaillard, S., Hao, J., Reynders, A., Malapert, P., Alonso, S., François, A., Barrere, C., Seal, R., Landry, M., Eschallier, A., Alloui, A., Bourinet, E., Delmas, P., LeFeuvre, Y., Moqrich, A., 2013. TAFA4, a Chemokine-like Protein, Modulates InjuryInduced Mechanical and Chemical Pain Hypersensitivity in Mice. Cell Rep. 5, 378-388. doi:10.1016/j.celrep.2013.09.013

Dichter, G.S., Felder, J.N., Bodfish, J.W., 2009. Autism is characterized by dorsal anterior cingulate hyperactivation during social target detection. Soc. Cogn. Affect. Neurosci. 4, 215-226. doi:10.1093/scan/nsp017

Ditzen, B., Neumann, I.D., Bodenmann, G., von Dawans, B., Turner, R. a., Ehlert, U., Heinrichs, M., 2007. Effects of different kinds of couple interaction on cortisol and heart rate responses to stress in women. Psychoneuroendocrinology 32, 565-574. 
doi:10.1016/j.psyneuen.2007.03.011

Dluzen, D.E., Muraoka, S., Landgraf, R., 1998. Olfactory bulb norepinephrine depletion abolishes vasopressin and oxytocin preservation of social recognition responses in rats. Neurosci. Lett. 254, 161-164. doi:10.1016/S0304-3940(98)00691-0

Domes, G., Heinrichs, M., Gläscher, J., Büchel, C., Braus, D.F., Herpertz, S.C., 2007a. Oxytocin Attenuates Amygdala Responses to Emotional Faces Regardless of Valence. Biol. Psychiatry 62, 1187-1190. doi:10.1016/j.biopsych.2007.03.025

Domes, G., Heinrichs, M., Michel, A., Berger, C., Herpertz, S.C., 2007b. Oxytocin Improves "Mind-Reading" in Humans. Biol. Psychiatry 61, 731-733. doi:10.1016/j.biopsych.2006.07.015

Domes, G., Lischke, A., Berger, C., Grossmann, A., Hauenstein, K., Heinrichs, M., Herpertz, S.C., 2010. Effects of intranasal oxytocin on emotional face processing in women. Psychoneuroendocrinology 35, 83-93. doi:10.1016/j.psyneuen.2009.06.016

Domes, G., Sibold, M., Schulze, L., Lischke, a, Herpertz, S.C., Heinrichs, M., 2013. Intranasal oxytocin increases covert attention to positive social cues. Psychol. Med. 43, 1747-53. doi: $10.1017 / \mathrm{S} 0033291712002565$

Eliava, M., Melchior, M., Knobloch-Bollmann, H.S., Wahis, J., da Silva Gouveia, M., Tang, Y., Ciobanu, A.C., Triana del Rio, R., Roth, L.C., Althammer, F., Chavant, V., Goumon, Y., Gruber, T., Petit-Demoulière, N., Busnelli, M., Chini, B., Tan, L.L., Mitre, M., Froemke, R.C., Chao, M. V., Giese, G., Sprengel, R., Kuner, R., Poisbeau, P., Seeburg, P.H., Stoop, R., Charlet, A., Grinevich, V., 2016. A New Population of Parvocellular Oxytocin Neurons Controlling Magnocellular Neuron Activity and Inflammatory Pain Processing. Neuron 89, 1291-1304. doi:10.1016/j.neuron.2016.01.041

Ellingsen, D.M., Wessberg, J., Chelnokova, O., Olausson, H., Laeng, B., Leknes, S., 2014. In touch with your emotions: Oxytocin and touch change social impressions while others' facial expressions can alter touch. Psychoneuroendocrinology 39, 11-20.

doi:10.1016/j.psyneuen.2013.09.017

Essick, G.K., James, A., McGlone, F.P., 1999. Psychophysical assessment of the affective components of non-painful touch. Neuroreport 10, 2083-2087. doi:10.1097/00001756199907130-00017

Fairhurst, M.T., Löken, L., Grossmann, T., 2014. Physiological and behavioral responses reveal 9month-old infants' sensitivity to pleasant touch. Psychol. Sci. 25, 1124-1131. doi: $10.1177 / 0956797614527114$

Feldman, R., Zagoory-Sharon, O., Weisman, O., Schneiderman, I., Gordon, I., Maoz, R., Shalev, I., Ebstein, R.P., 2012. Sensitive parenting is associated with plasma oxytocin and polymorphisms in the OXTR and CD38 genes. Biol. Psychiatry 72, 175-181. doi:10.1016/j.biopsych.2011.12.025

Ferguson, J.N., Aldag, J.M., Insel, T.R., Young, L.J., 2001. Oxytocin in the Medial Amygdala is Essential for Social Recognition in the Mouse. J. Neurosci. 21, 8278-8285. doi:21/20/8278 [pii] 
Ferguson, J.N., Young, L.J., Hearn, E.F., Matzuk, M.M., Insel, T.R., Winslow, J.T., Larry, J.Y., Hearn, E.F., Matzuk, M.M., Insel, T.R., Winslow, J.T., 2000. Social amnesia in mice lacking the oxytocin gene. Nat. Genet. 25, 284-8. doi:10.1038/77040

Field, T., 1980. Supplemental stimulation of preterm neonates. Early Hum. Dev. 4, 301-14. doi:http://dx.doi.org/10.1016/0378-3782(80)90033-X

Francis, D.D., Champagne, F.C., Meaney, M.J., 2000. Variations in maternal behaviour are associated with differences in oxytocin receptor levels in the rat. J. Neuroendocrinol. 12, 1145-1148. doi:10.1046/j.1365-2826.2000.00599.x

Gamer, M., Zurowski, B., Büchel, C., 2011. Correction for Baum et al., Preference of RIG-I for short viral RNA molecules in infected cells revealed by next-generation sequencing. Proc. Natl. Acad. Sci. U. S. A. 108, 3092. doi:10.1073/pnas.1100561108

Gimpl, G., Fahrenholz, F., Gene, C., 2001. The Oxytocin Receptor System : Structure, Function , and Regulation. Physiol. Rev. 81, 629-683.

Gong, L., Gao, F., Li, J., Li, J., Yu, X., Ma, X., Zheng, W., Cui, S., Liu, K., Zhang, M., Kunze, W., Liu, C.Y., 2015. Oxytocin-induced membrane hyperpolarization in pain-sensitive dorsal root ganglia neurons mediated by Ca2+/nNOS/NO/KATP pathway. Neuroscience 289, 417-428. doi:10.1016/j.neuroscience.2014.12.058

Gordon, I., Voos, A.C., Bennett, R.H., Bolling, D.Z., Pelphrey, K. A., Kaiser, M.D., 2013. Brain mechanisms for processing affective touch. Hum. Brain Mapp. 34, 914-922. doi:10.1002/hbm. 21480

Grewen, K.M., Girdler, S.S., Amico, J., Light, K.C., 2005. Effects of partner support on resting oxytocin, cortisol, norepinephrine, and blood pressure before and after warm partner contact. Psychosom. Med. 67, 531-538. doi:10.1097/01.psy.0000170341.88395.47

Guastella, A.J., Mitchell, P.B., Dadds, M.R., 2008. Oxytocin Increases Gaze to the Eye Region of Human Faces. Biol. Psychiatry 63, 3-5. doi:10.1016/j.biopsych.2007.06.026

Gustafsson, E., Levréro, F., Reby, D., Mathevon, N., 2013. Fathers are just as good as mothers at recognizing the cries of their baby. Nat. Commun. 4, 1698. doi:10.1038/ncomms2713

Gutierrez, S., Liu, B., Hayashida, K., Houle, T.T., Eisenach, J.C., 2013. Reversal of peripheral nerve injury-induced hypersensitivity in the postpartum period: role of spinal oxytocin. Anesthesiology 118, 152-9. doi:10.1097/ALN.0b013e318278cd21

Hofer, M. A, 1994. Early relationships as regulators of infant physiology and behavior. Acta Paediatr Suppl 397, 9-18. doi:10.1111/j.1651-2227.1994.tb13260.x

Hollander, E., Bartz, J., Chaplin, W., Phillips, A., Sumner, J., Soorya, L., Anagnostou, E., Wasserman, S., 2007. Oxytocin Increases Retention of Social Cognition in Autism. Biol. Psychiatry 61, 498-503. doi:10.1016/j.biopsych.2006.05.030

Holst, S., Uvnäs-Moberg, K., Petersson, M., 2002. Postnatal oxytocin treatment and postnatal stroking of rats reduce blood pressure in adulthood. Auton. Neurosci. Basic Clin. 99, 85-90. doi:10.1016/S1566-0702(02)00134-0 
Imanaka, A., Morinobu, S., Toki, S., Yamamoto, S., Matsuki, A., Kozuru, T., Yamawaki, S., 2008. Neonatal tactile stimulation reverses the effect of neonatal isolation on open-field and anxiety-like behavior, and pain sensitivity in male and female adult Sprague-Dawley rats. Behav. Brain Res. 186, 91-97. doi:10.1016/j.bbr.2007.07.039

Insel, T.R., Shapiro, L.E., 1992. Oxytocin receptor distribution reflects social organization in monogamous and polygamous voles. Proc. Natl. Acad. Sci. 89, 5981-5985.

Insel, T.R., Young, L.J., 2001. The neurobiology of attachment. Nat. Rev. Neurosci. 2, 129-136. doi: $10.1038 / 35053579$

Inui, K., Tsuji, T., Kakigi, R., 2006. Temporal analysis of cortical mechanisms for pain relief by tactile stimuli in humans. Cereb. Cortex 16, 355-365. doi:10.1093/cercor/bhi114

Jack, A., Connelly, J.J., Morris, J.P., James, P., 2012. DNA methylation of the oxytocin receptor gene predicts neural response to ambiguous social stimuli. Front. Hum. Neurosci. 6, 280. doi:10.3389/fnhum.2012.00280

Jo, Y.H., Stoeckel, M.E., Freund-Mercier, M.J., Schlichter, R., 1998. Oxytocin modulates glutamatergic synaptic transmission between cultured neonatal spinal cord dorsal horn neurons. J. Neurosci. 18, 2377-86.

Kendrick, K.M., Da Costa, A.P.C., Broad, K.D., Ohkura, S., Guevara, R., Lévy, F., Keverne, E.B., 1997. Neural control of maternal behaviour and olfactory recognition of offspring. Brain Res. Bull. 44, 383-395. doi:10.1016/S0361-9230(97)00218-9

Kendrick, K.M., Lévy, F., Keverne, E.B., 1992. Changes in the sensory processing of olfactory signals induced by birth in sleep. Science 256, 833-836. doi:10.1126/science.1589766

Kessner, S., Sprenger, C., Wrobel, N., Wiech, K., Bingel, U., 2013. Effect of oxytocin on placebo analgesia: A randomized study. Jama 310, 1733-1735. doi:10.1001/jama.2013.277446

Keverne, E.B., Curley, J.P., 2004. Vasopressin, oxytocin and social behaviour. Curr. Opin. Neurobiol. 14, 777-783. doi:10.1016/j.conb.2004.10.006

Krahé, C., Springer, A., Weinman, J. A, Fotopoulou, A., 2013. The social modulation of pain: others as predictive signals of salience - a systematic review. Front. Hum. Neurosci. 7, 386. doi:10.3389/fnhum.2013.00386

Kuhn, C.M., Pauk, J., Schanberg, S.M., 1990. Endocrine responses to mother-infant separation in developing rats. Developmental Psychobiology 23(5), 395-410

Kumsta, R., Hummel, E., Chen, F.S., Heinrichs, M., 2013. Epigenetic regulation of the oxytocin receptor gene: Implications for behavioral neuroscience. Front. Neurosci. 7, 1-6. doi:10.3389/fnins.2013.00083

Lechner, S.G., Lewin, G.R., 2013. Hairy sensation. Physiology (Bethesda). 28, 142-150. doi:10.1152/physiol.00059.2012

Lee, H.J., Macbeth, A.H., Pagani, J.H., Scott Young, W., 2009. Oxytocin: The great facilitator of life. Prog. Neurobiol. 88, 127-151. doi:10.1016/j.pneurobio.2009.04.001 
Leknes, S., Wessberg, J., Ellingsen, D.M., Chelnokova, O., Olausson, H., Laeng, B., 2013. Oxytocin enhances pupil dilation and sensitivity to "hidden" emotional expressions. Soc. Cogn. Affect. Neurosci. 8, 741-749. doi:10.1093/scan/nss062

Lenz, K.M., Sengelaub, D.R., 2010. Maternal care effects on the development of a sexually dimorphic motor system: The role of spinal oxytocin. Horm. Behav. 58, 575-581. doi:10.1016/j.yhbeh.2010.07.010

Levy, F., Kendrick, K.M., Goode, J. A, GuevaraGuzman, R., Keverne, E.B., 1995. Oxytocin and vasopressin release in the olfactory-bulb of parturient ewes - changes with maternal experience and effects on acetylcholine, gamma- aminobutyric-acid, glutamate and noradrenaline release. Brain Res. 669, 197-206.

Li, L., Rutlin, M., Abraira, V.E., Cassidy, C., Kus, L., Gong, S., Jankowski, M.P., Luo, W., Heintz, N., Koerber, H.R., Woodbury, C.J., Ginty, D.D., 2011. The functional organization of cutaneous low-threshold mechanosensory neurons. Cell 147, 1615-1627. doi:10.1016/j.cell.2011.11.027

Light, K.C., Grewen, K.M., Amico, J. A., 2005. More frequent partner hugs and higher oxytocin levels are linked to lower blood pressure and heart rate in premenopausal women. Biol. Psychol. 69, 5-21. doi:10.1016/j.biopsycho.2004.11.002

Liljencrantz, J., 2014. The role of the human C-tactile system in affective somatosensation and pain. Ph.D thesis, Institute of Neuroscience \& Physiology, University of Gothenburg, Gothenburg.

Liljencrantz, J., Björnsdotter, M., Morrison, I., Bergstrand, S., Ceko, M., Seminowicz, D. A., Cole, J., Bushnell, M.C., Olausson, H., 2013. Altered C-tactile processing in human dynamic tactile allodynia. Pain 154, 227-234. doi:10.1016/j.pain.2012.10.024

Liljencrantz, J., Marshall, A., Ackerley, R., Olausson, H., 2014. Discriminative and affective touch in human experimental tactile allodynia. Neurosci. Lett. 563, 75-79.

doi:10.1016/j.neulet.2014.01.041

Liljencrantz, J., Olausson, H., 2014. Tactile C fibers and their contributions to pleasant sensations and to tactile allodynia. Front. Behav. Neurosci. 8, 37. doi:10.3389/fnbeh.2014.00037

Liu, Q., Vrontou, S., Rice, F.L., Zylka, M.J., Dong, X., Anderson, D.J., 2007. Molecular genetic visualization of a rare subset of unmyelinated sensory neurons that may detect gentle touch. Nat. Neurosci. 10, 946-8. doi:10.1038/nn1937

Liu, R.C., Linden, J.F., Schreiner, C.E., 2006. Improved cortical entrainment to infant communication calls in mothers compared with virgin mice. Eur. J. Neurosci. 23, 3087-3097. doi:10.1111/j.1460-9568.2006.04840.x

Liu, Y., Wang, Z.X., 2003. Nucleus accumbens oxytocin and dopamine interact to regulate pair bond formation in female prairie voles. Neuroscience 121, 537-544. doi:10.1016/S03064522(03)00555-4

Loeser, J.D., Treede, R.D., 2008. The Kyoto protocol of IASP Basic Pain Terminology. Pain 137, 473-477. doi:10.1016/j.pain.2008.04.025 
Löken, L.S., Wessberg, J., Morrison, I., McGlone, F., Olausson, H., 2009. Coding of pleasant touch by unmyelinated afferents in humans. Nat. Neurosci. 12, 547-548. doi:10.1038/nn.2312

LoParo, D., Waldman, I.D., 2014. The oxytocin receptor gene (OXTR) is associated with autism spectrum disorder: a meta-analysis. Mol. Psychiatry 20, 1-7. doi:10.1038/mp.2014.77

Louvel, D., Delvaux, M., Felez, a, Fioramonti, J., Bueno, L., Lazorthes, Y., Frexinos, J., 1996. Oxytocin increases thresholds of colonic visceral perception in patients with irritable bowel syndrome. Gut 39, 741-747. doi:10.1136/gut.39.5.741

Lu, Y., Perl, E.R., 2003. A specific inhibitory pathway between substantia gelatinosa neurons receiving direct C-fiber input. J. Neurosci. 23, 8752-8758. doi:23/25/8752 [pii]

Lund, I., Lundeberg, T., Kurosawa, M., Uvnäs-Moberg, K., 1999. Sensory stimulation (massage) reduces blood pressure in unanaesthetized rats. J. Auton. Nerv. Syst. 78, 30-37. doi:10.1016/S0165-1838(99)00055-7

Lund, I., Yu, L.C., Uvnas-Moberg, K., Wang, J., Yu, C., Kurosawa, M., Agren, G., Rosén, A., Lekman, M., Lundeberg, T., 2002. Repeated massage-like stimulation induces long-term effects on nociception: Contribution of oxytocinergic mechanisms. Eur. J. Neurosci. 16, 330 338. doi:10.1046/j.1460-9568.2002.02087.x

Mameli, S., Pisanu, G.M., Sardo, S., Marchi, A., Pili, A., Carboni, M., Minerba, L., Trincas, G., Carta, M.G., Melis, M.R., Agabio, R., 2014. Oxytocin nasal spray in fibromyalgic patients. Rheumatol. Int. 34, 1047-1052. doi:10.1007/s00296-014-2953-y

Mancini, F., Beaumont, A.-L., Hu, L., Haggard, P., Iannetti, G.D., Iannetti, G.D.D., 2015. Touch inhibits subcortical and cortical nociceptive responses. Pain 156, 1936-44. doi:10.1097/j.pain.0000000000000253

Marlin, B.J., Mitre, M., D'amour, J. a., Chao, M. V., Froemke, R.C., 2015. Oxytocin enables maternal behaviour by balancing cortical inhibition. Nature 520, 499-504. doi:10.1038/nature14402

Maruyama, K., Shimoju, R., Ohkubo, M., Maruyama, H., Kurosawa, M., 2012. Tactile skin stimulation increases dopamine release in the nucleus accumbens in rats. J. Physiol. Sci. 62, 259-266. doi:10.1007/s12576-012-0205-Z

Matsuura, T., Kawasaki, M., Hashimoto, H., Ishikura, T., Yoshimura, M., Ohkubo, J.I., Maruyama, T., Motojima, Y., Sabanai, K., Mori, T., Ohnishi, H., Sakai, A., Ueta, Y., 2015. Fluorescent Visualisation of Oxytocin in the Hypothalamo-neurohypophysial/-spinal Pathways After Chronic Inflammation in Oxytocin-Monomeric Red Fluorescent Protein 1 Transgenic Rats. J. Neuroendocrinol. 27, 636-646. doi:10.1111/jne.12290

Matsuura, T., Kawasaki, M., Hashimoto, H., Yoshimura, M., Motojima, Y., Saito, R., Ueno, H., Maruyama, T., Ishikura, T., Sabanai, K., Mori, T., Ohnishi, H., Onaka, T., Sakai, A., Ueta, Y., 2016. Possible involvement of the rat hypothalamo-neurohypophysial/-spinal oxytocinergic pathways in acute nociceptive responses. J. Neuroendocrinol. doi:10.1111/jne.12396

Matthiesen, A.S., Ransjö-Arvidson, A.B., Nissen, E., Uvnäs-Moberg, K., 2001. Postpartum maternal oxytocin release by newborns: Effects of infant hand massage and sucking. Birth 28, 
13-19. doi:bir013 [pii]

Mazzuca, M., Minlebaev, M., Shakirzyanova, A., Tyzio, R., Taccola, G., Janackova, S., Gataullina, S., Ben-Ari, Y., Giniatullin, R., Khazipov, R., 2011. Newborn Analgesia Mediated by Oxytocin during Delivery. Front. Cell. Neurosci. 5, 3. doi:10.3389/fncel.2011.00003

McGlone, F., Olausson, H., Boyle, J. a., Jones-Gotman, M., Dancer, C., Guest, S., Essick, G., 2012. Touching and feeling: Differences in pleasant touch processing between glabrous and hairy skin in humans. Eur. J. Neurosci. 35, 1782-1788. doi:10.1111/j.1460-9568.2012.08092.x

McGlone, F., Wessberg, J., Olausson, H., 2014. Discriminative and affective touch: sensing and feeling. Neuron 82, 737-55. doi:10.1016/j.neuron.2014.05.001

Meyer-Lindenberg, A., Tost, H., 2012. Neural mechanisms of social risk for psychiatric disorders. Nat. Neurosci. 15, 663-668. doi:10.1038/nn.3083

Milenkovic, N., Wetzel, C., Moshourab, R., Lewin, G.R., 2008. Speed and temperature dependences of mechanotransduction in afferent fibers recorded from the mouse saphenous nerve. J. Neurophysiol. 100, 2771-2783. doi:10.1152/jn.90799.2008

Mitre, M., Marlin, B.J., Schiavo, J.K., Morina, E., Norden, S.E., Hackett, T. a, Aoki, C.J., Chao, M. V, Froemke, R.C., 2016. A Distributed Network for Social Cognition Enriched for Oxytocin Receptors. J. Neurosci. 36, 2517-35. doi:10.1523/JNEUROSCI.2409-15.2016

Mitsui, S., Yamamoto, M., Nagasawa, M., Mogi, K., Kikusui, T., Ohtani, N., Ohta, M., 2011. Urinary oxytocin as a noninvasive biomarker of positive emotion in dogs. Horm. Behav. 60, 239-243. doi:10.1016/j.yhbeh.2011.05.012

Moreno-López, Y., Martínez-Lorenzana, G., Condés-Lara, M., Rojas-Piloni, G., 2013. Identification of oxytocin receptor in the dorsal horn and nociceptive dorsal root ganglion neurons. Neuropeptides 47, 117-123. doi:10.1016/j.npep.2012.09.008

Morhenn, V., Beavin, L.E., Zak, P.J., 2012. Massage increases oxytocin and reduces adrenocorticotropin hormone in humans. Altern. Ther. Health Med. 18, 11-18.

Morrison, I., Löken, L.S., Olausson, H., 2010. The skin as a social organ. Exp. Brain Res. 204, 305-314. doi:10.1007/s00221-009-2007-y

Muhammad, A, Hossain, S., Pellis, S.M., Kolb, B., 2011. Tactile Stimulation During Development Attenuates Amphetamine Sensitization and Structurally Reorganizes Prefrontal Cortex and Striatum in a Sex-Dependent Manner. Behav. Neurosci. 125, 161-174. doi:10.1037/a0022628

Nagi, S.S., Rubin, T.K., Chelvanayagam, D.K., Macefield, V.G., Mahns, D. A, 2011. Allodynia mediated by C-tactile afferents in human hairy skin. J. Physiol. 589, 4065-75. doi:10.1113/jphysiol.2011.211326

Neumann, I.D., Krömer, S.A., Toschi, N., Ebner, K., 2000. Brain oxytocin inhibits the (re)activity of the hypothalamo-pituitary-adrenal axis in male rats: Involvement of hypothalamic and limbic brain regions. Regul. Pept. 96, 31-38. doi:10.1016/S0167-0115(00)00197-X

Oettl, L.L., Ravi, N., Schneider, M., Scheller, M.F., Schneider, P., Mitre, M., da Silva Gouveia, M., 
Froemke, R.C., Chao, M. V., Young, W.S., Meyer-Lindenberg, A., Grinevich, V., Shusterman, R., Kelsch, W., 2016. Oxytocin Enhances Social Recognition by Modulating Cortical Control of Early Olfactory Processing. Neuron 90, 609-621. doi:10.1016/j.neuron.2016.03.033

Ohlsson, B., Truedsson, M., Bengtsson, M., Torstenson, R., Sjölund, K., Björnsson, E.S., Simrèn, M., 2005. Effects of long-term treatment with oxytocin in chronic constipation; a double blind, placebo-controlled pilot trial. Neurogastroenterol. Motil. 17, 697-704. doi:10.1111/j.13652982.2005.00679.x

Okabe, S., Yoshida, M., Takayanagi, Y., Onaka, T., 2015. Activation of hypothalamic oxytocin neurons following tactile stimuli in rats. Neurosci. Lett. 600, 22-27. doi:10.1016/j.neulet.2015.05.055

Olausson, H., Lamarre, Y., Backlund, H., Morin, C., Wallin, B.G., Starck, G., Ekholm, S., Strigo, I., Worsley, K., Vallbo, Å B., Bushnell, M.C., 2002. Unmyelinated tactile afferents signal touch and project to insular cortex. Nat. Neurosci. 5, 900-4. doi:10.1038/nn896

Paloyelis, Y., Doyle, O.M., Zelaya, F.O., Maltezos, S., Williams, S.C., Fotopoulou, A., Howard, M. A., 2016a. A Spatiotemporal Profile of In Vivo Cerebral Blood Flow Changes Following Intranasal Oxytocin in Humans. Biol. Psychiatry 79, 693-705. doi:10.1016/j.biopsych.2014.10.005

Paloyelis, Y., Krahé, C., Maltezos, S., Williams, S.C., Howard, M. A, Fotopoulou, A., 2016b. The Analgesic Effect Of Oxytocin In Humans: A Double-Blinded Placebo Controlled Cross-Over Study Using Laser-Evoked Potentials. J. Neuroendocrinol. n/a-n/a. doi:10.1111/jne.12347

Parker, K.J., Buckmaster, C.L., Sundlass, K., Schatzberg, A.F., Lyons, D.M., 2006. Maternal mediation, stress inoculation, and the development of neuroendocrine stress resistance in primates. Proc. Natl. Acad. Sci. U. S. A. 103, 3000-3005. doi:10.1073/pnas.0506571103

Pedersen, C. A, Prange, A.J., 1979. Induction of maternal behavior in virgin rats after intracerebroventricular administration of oxytocin. Proc. Natl. Acad. Sci. U. S. A. 76, 6661-5. doi:10.1073/pnas.76.12.6661

Petersson, M., Alster, P., Lundeberg, T., Uvnäs-Moberg, K., 1997. Oxytocin causes a long-term decrease of blood pressure in female and male rats. Physiol. Behav. 60, 1311-1315. doi:10.1016/S0031-9384(96)00261-2

Petersson, M., Hulting, A.L., Uvnäs-Moberg, K., 1999. Oxytocin causes a sustained decrease in plasma levels of corticosterone in rats. Neurosci. Lett. 264, 41-44. doi:10.1016/S03043940(99)00159-7

Petersson, M., Uvnäs-Moberg, K., Erhardt, S., Engberg, G., 1998. Oxytocin increases locus coeruleus alpha 2-adrenoreceptor responsiveness in rats. Neurosci. Lett. 255, 115-118. doi:10.1016/S0304-3940(98)00729-0

Popik, P., Van Ree, J.M., 1991. Oxytocin but not vasopressin facilitates social recognition following injection into the medial preoptic area of the rat brain. Eur. Neuropsychopharmacol. $1,555-60$.

Popik, P., Vetulani, J., van Ree, J.M., 1992. Low doses of oxytocin facilitate social recognition in 
rats. Psychopharmacology (Berl). 106, 71-74. doi:10.1007/BF02253591

Puglia, M.H., Lillard, T.S., Morris, J.P., Connelly, J.J., 2015. Epigenetic modification of the oxytocin receptor gene influences the perception of anger and fear in the human brain. Proc. Natl. Acad. Sci. 112, 3308-3313. doi:10.1073/pnas. 1422096112

Qiu, F., Qiu, C.Y., Cai, H., Liu, T.T., Qu, Z.W., Yang, Z., Li, J. Da, Zhou, Q.Y., Hu, W.P., 2014. Oxytocin inhibits the activity of acid-sensing ion channels through the vasopressin, V1A receptor in primary sensory neurons. Br. J. Pharmacol. 171, 3065-3076. doi:10.1111/bph.12635

Rash, J. A., Campbell, T.S., 2014. The Effect of Intranasal Oxytocin Administration on Acute Cold Pressor Pain. Psychosom. Med. 76, 422-429. doi:10.1097/PSY.0000000000000068

Rash, J. A, Aguirre-camacho, A., Campbell, T.S., 2014. Oxytocin And Pain. Clin. J. Pain 30, 453462. doi:10.1097/AJP.0b013e31829f57df

Richter, K., Wolf, G., Engelmann, M., 2005. Social recognition memory requires two stages of protein synthesis in mice. Learn. Mem. 12, 407-413. doi:10.1101/lm.97505

Riem, M.M.E., Bakermans-Kranenburg, M.J., Pieper, S., Tops, M., Boksem, M.A.S., Vermeiren, R.R.J.M., Van Ijzendoorn, M.H., Rombouts, S. A.R.B., 2011. Oxytocin modulates amygdala, insula, and inferior frontal gyrus responses to infant crying: A randomized controlled trial. Biol. Psychiatry 70, 291-297. doi:10.1016/j.biopsych.2011.02.006

Riem, M.M.E., van IJzendoorn, M.H., Tops, M., Boksem, M. A S., Rombouts, S.A.R.B., Bakermans-Kranenburg, M.J., 2012. No Laughing Matter: Intranasal Oxytocin Administration Changes Functional Brain Connectivity during Exposure to Infant Laughter. Neuropsychopharmacology 37, 2174-2174. doi:10.1038/npp.2012.27

Rimmele, U., Hediger, K., Heinrichs, M., Klaver, P., 2009. Oxytocin makes a face in memory familiar. J. Neurosci. 29, 38-42. doi:10.1523/JNEUROSCI.4260-08.2009

Rothschild, G., Cohen, L., Mizrahi, A., Nelken, I., 2013. Elevated correlations in neuronal ensembles of mouse auditory cortex following parturition. J. Neurosci. 33, 12851-12861. doi:10.1523/JNEUROSCI.4656-12.2013

Russo, R., D’Agostino, G., Mattace Raso, G., Avagliano, C., Cristiano, C., Meli, R., Calignano, A., 2012. Central administration of oxytocin reduces hyperalgesia in mice: Implication for cannabinoid and opioid systems. Peptides 38, 81-88. doi:10.1016/j.peptides.2012.08.005

Salter, M.W., Henry, J.L., 1990. Differential responses of nociceptive vs. non-nociceptive spinal dorsal horn neurones to cutaneously applied vibration in the cat. Pain 40, 311-322. doi:10.1016/0304-3959(90)91128-6

Savaskan, E., Ehrhardt, R., Schulz, A., Walter, M., Schächinger, H., 2008. Post-learning intranasal oxytocin modulates human memory for facial identity. Psychoneuroendocrinology 33, 368374. doi:10.1016/j.psyneuen.2007.12.004

Seal, R.P., Wang, X., Guan, Y., Raja, S.N., Woodbury, C.J., Basbaum, A.I., Edwards, R.H., 2009. Injury-induced mechanical hypersensitivity requires $\mathrm{C}$-low threshold mechanoreceptors. 
Skuse, D.H., Lori, A., Cubells, J.F., Lee, I., Conneely, K.N., Puura, K., Lehtimäki, T., Binder, E.B., Young, L.J., 2014. Common polymorphism in the oxytocin receptor gene (OXTR) is associated with human social recognition skills. Proc. Natl. Acad. Sci. U. S. A. 111, 1987-92. doi:10.1073/pnas.1302985111

Stock, S., Uvnäs-Moberg, K., 1988. Increased plasma levels of oxytocin in response to afferent electrical stimulation of the sciatic and vagal nerves and in response to touch and pinch in anaesthetized rats. Acta Physiol. Scand. 132, 29-34. doi:10.1111/j.1748-1716.1988.tb08294.x

Stoop, R., 2014. Neuromodulation by oxytocin and vasopressin in the central nervous system as a basis for their rapid behavioral effects. Curr. Opin. Neurobiol. 29, 187-193. doi:10.1016/j.conb.2014.09.012

Thompson, R.J., Parker, K.J., Hallmayer, J.F., Waugh, C.E., Gotlib, I.H., 2011. Oxytocin receptor gene polymorphism (rs2254298) interacts with familial risk for psychopathology to predict symptoms of depression and anxiety in adolescent girls. Psychoneuroendocrinology 36, 144147. doi:10.1016/j.psyneuen.2010.07.003

Tracy, L.M., Georgiou-Karistianis, N., Gibson, S.J., Giummarra, M.J., 2015. Oxytocin and the modulation of pain experience: Implications for chronic pain management. Neurosci. Biobehav. Rev. 55, 53-67. doi:10.1016/j.neubiorev.2015.04.013

Treede, R.D., Kenshalo, D.R., Gracely, R.H., Jones, A.K.P., 1999. The cortical representation of pain. Pain 79, 105-111. doi:10.1016/S0304-3959(98)00184-5

Trotter, P.D., McGlone, F., McKie, S., McFarquhar, M., Elliott, R., Walker, S.C., Deakin, J.F.W., 2016. Effects of acute tryptophan depletion on central processing of CT-targeted and discriminatory touch in humans. Eur. J. Neurosci. 1-12. doi:10.1111/ejn.13298

Uvnäs-Moberg, K., Ahlenius, S., Hillegaart, V., Alster, P., 1994. High doses of oxytocin cause sedation and low doses cause an anxiolytic-like effect in male rats. Pharmacol. Biochem. Behav. 49, 101-106. doi:10.1016/0091-3057(94)90462-6

Uvnäs-Moberg, K., Alster, P., Hillegaart, V., Ahlenius, S., 1992. Oxytocin reduces exploratory motor behaviour and shifts the activity towards the centre of the arena in male rats. Acta Physiol. Scand. 145, 429-30. doi:10.1111/j.1748-1716.1992.tb09385.x

Uvnäs-Moberg, K., Alster, P., Lund, I., Lundeberg, T., Kurosawa, M., Ahlenius, S., 1996. Stroking of the abdomen causes decreased locomotor activity in conscious male rats. Physiol. Behav. 60, 1409-1411. doi:10.1016/S0031-9384(96)00226-0

Uvnäs-Moberg, K., Alster, P., Petersson, M., 1996. Dissociation of oxytocin effects on body weight in two variants of female Sprague-Dawley rats. Integr. Physiol. Behav. Sci. 31, 44-55.

Uvnas-Moberg, K., Alster, P., Petersson, M., Sohlstrom, A., Bjorkstrand, E., 1998. Postnatal oxytocin injections cause sustained weight gain and increased nociceptive thresholds in male and female rats. Pediatr Res 43, 344-348. doi:10.1203/00006450-199803000-00006

Uvnäs-Moberg, K., Eklund, M., Hillegaart, V., Ahlenius, S., 2000. Improved conditioned avoidance 
learning by oxytocin administration in high-emotional male Sprague-Dawley rats. Regul. Pept. 88, 27-32. doi:10.1016/S0167-0115(99)00112-3

Uvnäs-Moberg, K., Handlin, L., Petersson, M., 2014. Self-soothing behaviors with particular reference to oxytocin release induced by non-noxious sensory stimulation. Front. Psychol. 5, 1529. doi:10.3389/fpsyg.2014.01529

Vallbo, Å.B., Olausson, H., Wessberg, J., 1999. Unmyelinated afferents constitute a second system coding tactile stimuli of the human hairy skin. J. Neurophysiol. 81, 2753-2763.

van Leengoed, E., Kerker, E., Swanson, E., 1987. Inhibition of post partum maternal-behaviour in the rat by injecting an oxytocin antagonist into the cerebral ventricles. J. Endocrinol. 112, 275282.

van Oers, H.J.J., de Kloet, E.R., Whelan, T., Levine, S., 1998. Maternal deprivation effect on the infant's neural stress markers is reversed by tactile stimulation and feeding but not by suppressing corticosterone. J. Neurosci. 18, 10171-10179.

Vannorsdall, T., Dahlquist, L., J, P., Power, T., 2004. The relation between nonessential touch and children's distress during lumbar punctures. Child. Heal. Care 33, 299-315 17p. doi:10.1207/s15326888chc3304

Vrontou, S., Wong, A.M., Rau, K.K., Koerber, H.R., Anderson, D.J., 2013. Genetic identification of $\mathrm{C}$ fibres that detect massage-like stroking of hairy skin in vivo. Nature 493, 669-73. doi:10.1038/nature11810

Wacker, D.W., Ludwig, M., 2012. Vasopressin, oxytocin, and social odor recognition. Horm. Behav. 61, 259-265. doi:10.1016/j.yhbeh.2011.08.014

Walker, S.C., McGlone, F.P., 2013. The social brain: Neurobiological basis of affiliative behaviours and psychological well-being. Neuropeptides 47, 379-393. doi:10.1016/j.npep.2013.10.008

Wang, Y.L., Yuan, Y., Yang, J., Wang, C.H., Pan, Y.J., Lu, L., Wu, Y.Q., Wang, D.X., Lv, L.X., Li, R.R., Xue, L., Wang, X.H., Bi, J.W., Liu, X.F., Qian, Y.N., Deng, Z.K., Zhang, Z.J., Zhai, X.H., Zhou, X.J., Wang, G.L., Zhai, J.X., Liu, W.Y., 2013. The interaction between the oxytocin and pain modulation in headache patients. Neuropeptides 47, 93-97. doi:10.1016/j.npep.2012.12.003

Wei, B., Tai, F., Liu, X., Ma, L., Yang, X., Jia, R., Zhang, X., 2013. Neonatal tactile stimulation alleviates the negative effects of neonatal isolation on novel object recognition, sociability and neuroendocrine levels in male adult mandarin voles (Microtus mandarinus). Physiol. Behav. 112-113, 14-22. doi:10.1016/j.physbeh.2013.02.005

Witt, D.M., Winslow, J.T., Insel, T.R., 1992. Enhanced social interactions in rats following chronic, centrally infused oxytocin. Pharmacol. Biochem. Behav. 43, 855-861. doi:10.1016/00913057(92)90418-F

Wrobel, L., Schorscher-Petcu, A., Dupré, A., Yoshida, M., Nishimori, K., Tribollet, E., 2011. Distribution and identity of neurons expressing the oxytocin receptor in the mouse spinal cord. Neurosci. Lett. 495, 49-54. doi:10.1016/j.neulet.2011.03.033 
Yang, H.-P., Wang, L., Han, L., Wang, S.C., 2013. Nonsocial functions of hypothalamic oxytocin. ISRN Neurosci. 2013, 179272. doi:10.1155/2013/179272

Yoshida, M., Takayanagi, Y., Inoue, K., Kimura, T., Young, L.J., Onaka, T., Nishimori, K., 2009. Evidence That Oxytocin Exerts Anxiolytic Effects via Oxytocin Receptor Expressed in Serotonergic Neurons in Mice. J. Neurosci. 29, 2259-2271. doi:10.1523/jneurosci.559308.2009

Young, L.J., Wang, Z., 2004. The neurobiology of pair bonding. Nat. Neurosci. 7, 1048-1054. doi:10.1038/nn1327

Zunhammer, M., Geis, S., Busch, V., Greenlee, M.W., Eichhammer, P., 2015. Effects of Intranasal Oxytocin on Thermal Pain in Healthy Men: A Randomized Functional Magnetic Resonance Imaging Study. Psychosom. Med. 77, 156-166. 